\title{
In vitro synthesis of tensioned synoviocyte bioscaffolds for meniscal fibrocartilage tissue engineering
}

\author{
Jennifer J Warnock ${ }^{1 *}$, Lindsay Baker ${ }^{1,2}$, George A Ballard ${ }^{1,3}$ and Jesse Ott ${ }^{1}$
}

\begin{abstract}
Background: Meniscal injury is a common cause of lameness in the dog. Tissue engineered bioscaffolds may be a treatment option for meniscal incompetency, and ideally would possess meniscus- like extracellular matrix (ECM) and withstand meniscal tensile hoop strains. Synovium may be a useful cell source for meniscal tissue engineering because of its natural role in meniscal deficiency and its in vitro chondrogenic potential. The objective of this study is to compare meniscal -like extracellular matrix content of hyperconfluent synoviocyte cell sheets ("HCS") and hyperconfluent synoviocyte sheets which have been tensioned over wire hoops (tensioned synoviocyte bioscaffolds, "TSB") and cultured for 1 month.

Results: Long term culture with tension resulted in higher GAG concentration, higher chondrogenic index, higher collagen concentration, and type II collagen immunoreactivity in TSB versus HCS. Both HCS and TSB were immunoreactive for type I collagen, however, HCS had mild, patchy intracellular immunoreactivity while TSB had diffuse moderate immunoreactivity over the entire bisocaffold. The tissue architecture was markedly different between TSB and HCS, with TSB containing collagen organized in bands and sheets. Both HCS and TSB expressed alpha smooth muscle actin and displayed active contractile behavior. Double stranded DNA content was not different between TSB and HCS, while cell viability decreased in TSB.
\end{abstract}

Conclusions: Long term culture of synoviocytes with tension improved meniscal- like extra cellular matrix components, specifically, the total collagen content, including type I and II collagen, and increased GAG content relative to HCS.

Future research is warranted to investigate the potential of TSB for meniscal tissue engineering.

\section{Background}

Meniscal injuries are a common cause of painful stifle arthritis and joint dysfunction in dogs and humans [1-6]. Despite intensive research over several decades, a cure for meniscal deficiency has not been found. Thus tissue engineering is being investigated as a means for inducing meniscal healing or regeneration, through producing fibrocartilage neotissues in the laboratory, utilizing cell culture, scaffold use, and in vitro biomechanical stimulation.

Tissue engineering scaffolds mechanically support cell growth and guide tissue formation, and have been surgically implanted in dogs [7-9]. An ideal cell scaffold for

\footnotetext{
* Correspondence: jennifer.warnock@oregonstate.edu

${ }^{1}$ Clinical Sciences, College of Veterinary Medicine, Oregon State University, Corvallis, OR, USA

Full list of author information is available at the end of the article
}

meniscal tissue engineering and in vivo implantation would have physiologically relevant, meniscus like extracellular matrix (ECM) and biomechanical properties. Synthetic polymer scaffolds such as porous polyurethane [10] poly vinyl alcohol hydrogel [11], polyglycolic acid mesh [12], 75:25 poly(lactic-co-glycolic acid)[13], l-lactide $\varepsilon$-caprolactone co-polymer [14], poly(L-co-D,L-lactic acid)/ poly(caprolactone-triol) [15], small intestinal submucosa [8], collagen gels [16], and pure collagen scaffolds [17,18], have been investigated for the treatment of meniscal deficiency. While these implants partially replace meniscal function, scaffolds may be complicated by progressive chemical breakdown, structural weakening, lack of lubricity, inadequate integration with the recipients' tissues [19], articular cartilage contact damage [20] and inflammatory reactions [18] incited by allogenic or xenogenic scaffold content [21].

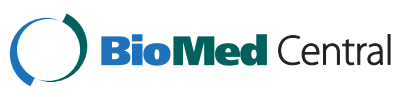


As harvest of autologous meniscal cells would cause patient injury, this study used canine osteoarthritic, autogenous joint- origin synoviocytes obtained from arthroscopic debris collected during clinically indicated stifle surgery. To avoid additional patient morbidity, synoviocytes from normal, unaffected joints were not utilized; additionally, normal canine synovium has been found to have less chondrogenic potential compared to infrapatellar fat pad [22]. In rats, mice, and humans, synovium is superior to other cell sources, including periosteum, bone marrow, muscle, and adipose, for in vitro chondrogenesis [23-25]. In the dog, osteoarthritic joint-origin synovial cells can produce components of meniscal fibrocartilage in vitro [26,27] and are readily obtained minimally invasively [28]. In vivo, canine osteoarthritic joint- origin synoviocytes are responsible for cellular repopulation of meniscal grafts [29] and undergo spontaneous fibrochondrogenesis [30], including formation of a meniscal-like regenerate in meniscectomized stifles [31]. Synovial pedicle grafts and free synovial grafts have been used to achieve partial avascular meniscal healing in dogs and rabbits [32-35] and are superior to muscle flaps and synthetic meshes in dogs [33]. Use of living, autologous bioscaffolds with these regenerative properties could be advantageous over use of synthetic scaffolds for augmenting meniscal healing or treating meniscal loss.

Recently, scaffold-free tissue-engineered constructs cultured from synovial mesenchymal stem cells were used to successfully induce healing of meniscal defects [36] in pigs. Thus, given this success in the pig, and to avoid the complications of scaffold use, the objective of this study is to produce autologous fibrocartilage bioscaffolds, which in the future may be utilized in the dog as surgical implants without synthetic, xenogenic, or allogenic components. We hypothesize that the long term application of tension to synoviocytes will result in formation of a collagenous bioscaffold, with greater cell viability, and increased meniscal-like extracellular matrix content and architecture, versus synoviocytes grown short term in hyperconfluent monolayer culture.

\section{Methods}

\section{Tissue harvest}

With informed owner consent, synovium was obtained from 10 dogs with naturally occurring clinical osteoarthritis as per institutional Animal Care and Use Committee Protocol. Dogs were treated for degeneration of the cranial cruciate ligament and medial meniscal injury via exploratory arthroscopy, partial meniscectomy if indicated, and tibial plateau leveling osteotomy or lateral tibiofabellar suture. Synovial villi were arthroscopically harvested during routine partial synovectomy, only as clinically required, using a tissue shaver (Stryker, San
Jose, CA) with a $3.5 \mathrm{~mm}$ aggressive shaver blade run at $1800 \mathrm{rpm}$ [28]. Dogs with a history of steroid administration, or dogs with concurrent disease processes were excluded from the study.

Harvested synovial villi were immediately placed in a $50 \mathrm{~mL}$ polypropylene tube containing $40 \mathrm{~mL}$ of Dulbeccos' Modified Eagle's Media (DMEM) with 10\% fetal bovine serum (FBS), warmed to $37^{\circ} \mathrm{C}$. The tube was then transported immediately to the laboratory and centrifuged at 313 g, media was decanted, and resultant tissue pellet weighed, and transferred by pipette to a digestion solution as described below.

\section{Cell culture}

Tissue fragments were completely digested with sterile Type 1A clostridial collagenase $10 \mathrm{mg} / \mathrm{mL}$ in RPMI 1640 solution over $2-6$ hours at $37^{\circ} \mathrm{C}$. Tissue was deemed to be completely digested when no ECM could be visualized grossly. Cells were cultured in monolayer for 4 passages to isolate Type B fibroblast-like synoviocytes [37] and Type $C$ intermediate synoviocytes [37]. The following media formulation was used for the duration of culture: high glucose DMEM with phenol red $\mathrm{pH}$ indicator, supplemented with $17.7 \%$ FBS, $0.021 \mathrm{mg} / \mathrm{mL}$ glycine, $0.025 \mathrm{mg} / \mathrm{mL}$ L-alanine, $0.037 \mathrm{mg} / \mathrm{mL} \mathrm{L}$ - asparagine, $0.038 \mathrm{mg} / \mathrm{mL}$ L-aspartic acid, $0.042 \mathrm{mg} / \mathrm{mL}$ L-glutamic acid, $0.033 \mathrm{mg} / \mathrm{mL}$ L-proline, $0.030 \mathrm{mg} / \mathrm{mL} \mathrm{L}$-serine, $0.23 \mathrm{mg} / \mathrm{mL}$ pyruvate, $0.52 \mathrm{mg} / \mathrm{mL}$ L-glutamine, $6.75 \mathrm{mg} /$ $\mathrm{mL}$ HEPES buffer, 177.0 units $/ \mathrm{mL}$ penicillin, $177.0 \mu \mathrm{g} / \mathrm{mL}$ streptomycin, and $0.44 \mathrm{ug} / \mathrm{mL}$ amphoterocin (supplemented DMEM, "sDMEM"). The flasks were incubated at canine body temperature, at $37.8^{\circ} \mathrm{C}$, and at $5 \% \mathrm{CO}_{2}, 95 \%$ humidity, with sterile media change performed every 24 hours.

For each dog, synoviocytes were passaged when 95\% monolayer confluence was reached. For all dogs at $4^{\text {th }}$ passage a mean of $6,300,000 \pm 10,000$ cells per flask were seeded into eighteen $150 \mathrm{~cm}^{2}$ flasks. These $4^{\text {th }}$ passage cells were allowed to become hyperconfluent monolayer cell sheets ("HCS"), defined as cells overlapping each other in greater than 100\% confluency (Figure 1A). When HCS began to spontaneously contract off the corners of the flask floor (Figure 1B), they were completely dislodged off the flask floors by gentle pushing with the pipette tip. At this time $3 \mathrm{HCS}$ per dog were harvested for tissue analyses (as described below), 6 were required for use in another unrelated study, and the remaining 9 were used to make tensioned synoviocyte bioscaffolds (TSB).

To synthesize TSB (Figure 2), each HCS was moved from the flask to a 6 -well plate without touching the flask nozzle, using a $10 \mathrm{~mL}$ pipettor and gentle continuous suction. The HCS was gently discharged into a $10 \mathrm{~mL}$ media well, filled with the above described media to prevent cell sheet desiccation. A $2.0 \mathrm{~cm}$ diameter 


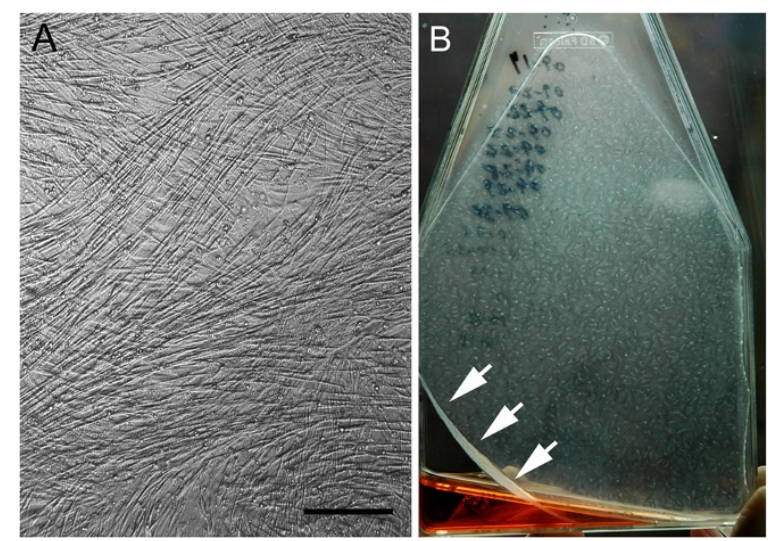

Figure 1 Representative hyperconfluent cell sheets: Phase contrast microscopy of $4^{\text {th }}$ passage hyperconfluent cell sheet ("HCS"; A), 10X objective magnification, bar $=100 \mu \mathrm{m}$. Gross appearance of a representative hyperconfluent $4^{\text {th }}$ passage cells sheet at commencement of spontaneous sheet contraction (arrows), indicating time for sheet harvest to synthesize tensioned synoviocyte bioscaffolds (B).

22ga wire hoop was placed over the cell sheet. While grasping the twist on the wire hoop with a tissue forceps, the hyperconfluent cell sheet was pulled around the hoop using Bishop Harmon forceps. The hypercondfluent cell sheet was pulled over the hoop three times with approximately $0.5 \mathrm{~N}$ of tension to avoid tearing, making a tensioned bioscaffold. Then the completed TSB was placed on the bottom of the well with the free end down to prevent unraveling. TSB were cultured for an additional 30 days with daily media changes and then harvested for tissue analyses as described below.

\section{Tissue analyses}

Tissue analyses of HCS and TSB examined presence of ECM which is functionally critical in the normal meniscus: type I collagen which accounts for the preponderance of meniscal collagen [38]; type II collagen, which accounts for a small amount primarily localized to the axial meniscus, [38] $\alpha$ - smooth muscle actin (ASM), [39-41]; and glycosaminoglycans (GAG) [42-44], including aggrecan [45].

\section{Cell viability}

During monolayer culture, cell viability counts were performed using the trypan blue exclusion assay [46] at each passage on all dogs. One HCS each from 3 dogs and one TSB each from all dogs were washed three times in sterile phosphate buffered saline and immersed in $4 \mu \mathrm{M}$ ethidium homodimer and $6 \mu \mathrm{M}$ acetomethoxy calcein (calcein -AM) solution (Ethidium homodimer and Calcein AM Live/ Dead Viability Assay, Invitrogen, Carlsbad, CA) for 20 minutes at $37.8^{\circ} \mathrm{C}, 5 \% \mathrm{CO} 2,95 \%$ humidity. Live and dead cell counts were performed by hand on 6 regions ( 3 of the periphery and 3 of the center) of each construct, where cells could be clearly visualized in one plane, using a laser microscope (Eclipse Ti-u Laser Microscope, Nikkon, Japan). Due to the complex three -dimensional nature of the neotissues, these cell counts provided an estimate of cell viability.

\section{Histology}

Formalin-fixed and paraffin embedded sections of one HCS and two TSB per dog were stained with Hematoxylin and Eosin, Masson's trichrome, and Toluidine Blue.

For immunohistochemistry, tissues were sectioned at 4-5 $\mu \mathrm{m}$ and sections were collected on charged slides and baked at $60^{\circ} \mathrm{C}$ for 1 hour. Slides were rehydrated through two washes of xylene, two washes of $100 \%$ ethanol, and one wash of $80 \%$ ethanol and water. Slides to be stained for collagen were pretreated with a pepsin digestion of $0.1 \%$ pepsin in $0.1 \mathrm{M} \mathrm{HCl}$ at $37^{\circ} \mathrm{C}$ for $5 \mathrm{mi}-$ nutes. All slides were rinsed in Tris buffered saline (TBS), placed on an autostainer and washed in TBS followed by $3 \% \mathrm{H}_{2} \mathrm{O}_{2}$ in TBS for 5 minutes. Then serum-free protein block (Serum Free Protein Block, Dako, Carpinteria CA, \#X0909) was applied for $10 \mathrm{mi}-$ nutes, with excess blown off. The primary antibodies were diluted in a proprietary antibody diluent (Antibody Diluent, Dako, Carpinteria, CA) to the following concentrations: Collagen I (rabbit Collagen Type I Antibody (\#AB749P), Millipore, Temecula, CA) 1:100, Collagen II (rabbit Collagen Type II Antibody (\#AB746P), Millipore, Temecula, CA), 1:100; alpha smooth muscle actin (mouse Alpha Smooth Muscle Actin Antibody (\#M0851), Dako, Carpinteria, CA)1:30; and mouse or rabbit universal negative control antibodies (Universal Negative Control, Dako, Carpinteria, CA) were used to test for non-specific immunoreactivity. Antibodies were applied to experimental neotissues or control tissues for 30 minutes at room temperature. Positive control tissues (Envision + HRP, Dako, Carpinteria, CA) type II collagen included canine articular cartilage, meniscus, and tracheal cartilage; for type I collagen, meniscus, tendon, and skin; small intestine for $\alpha$ - smooth muscle actin; and lymph node for macrophages. After washing in TBS, secondary antibodies were applied for 30 minutes at room temperature, then washed again with TBS. The chromogen (Nova Red, Vector Laboratories, Burlingame, CA) was applied for 5 minutes as directed by the manufacturer, and washed in deionized water followed by hematoxylin for 5 minutes, rinsed again in deionized water, then rinsed in TBS, and coverslipped.

Histologic specimens were examined completely at 10x and 20x objective magnification (Zeiss Microscope, Thornwood, NY) and images of each section were captured by a digital camera (Olympus DP-70 Digital Camera, Olympus, Melville, NY). Immunoreactivity staining intensity for each was rated as originally described by 
Figure 2 Illustration of tensioned synoviocyte bioscaffold synthesis: 1) the hyperconfluent cell sheet ("HCS") is moved to the cell culture well using a pipette tip; 2 ) the wire hoop is placed over the HCS; 3 ) while holding the wire twist with a forceps, the HCS is doubled over one end of the wire hoop; 4) the ends of the doubled over HCS are grasped with forceps and tension is applied perpendicular to the wire hoop; 5) the HCS is wrapped over the opposite side of the wire hoop; 6) the triple wrap is finished, creating a tensioned synoviocyte bioscaffold with six cell layers.

Wakshlag et al. [47] with a few modifications: immunoreactivity was localized to intracellular or extracellular staining and intensity was described as weak, moderate, and strong staining. Intracellular and extracellular immunoreactivity was described as being rare if $<10 \%$ of the cells or ECM area was positively stained, patchy if $10-50 \%$ of cells or ECM were stained, and diffuse if $>50 \%$ of cells or ECM was stained.

\section{Tissue weight}

One HCS and one TSB per dog were lyophilized and a dry weight obtained. Samples were digested in $1.0 \mathrm{ml}$ Papain Solution (2 mM Dithiothreitol and 300ug/ml Papain) at $60^{\circ} \mathrm{C}$ in a water bath for 24 hours. This papain digest solution was used to obtain double stranded DNA (dsDNA), GAG, and collagen content of the HCS and TSB.

\section{DNA quantification}

Double stranded DNA quantification assay (The Quant-iT PicoGreen $^{\mathrm{Tm}}$ Assay, Invitrogen Carlsbad, CA) was performed per manufacturer's instructions; double stranded DNA extracted from bovine thymus was used to create standards of 1,000,100,10, and $1 \mathrm{ng} / \mathrm{mL}$. Standard and sample fluorescence was read by a fluorometer (Qubit, Invitrogen, Carlsbad CA) at $485 \mathrm{~nm}$ excitation/ $528 \mathrm{~nm}$ emission and dsDNA was determined based on the standard curve.

\section{Biochemical extracellular matrix assays}

Glycosaminglycan content was determined by the dimethyl-methylene blue sulfated glycosaminoglycan assay [48] using a spectrophotometer (Synergy HT- KC4 Spectrophotometric Plate Reader and FT4software, BioTec, Winooski, VT). The Chondrogenic Index was calculated using the following equation: [ $\mu$ g GAG/ ug dsDNA] [49] and $[\mu \mathrm{g}$ collagen/ ug dsDNA] to identify chondrogenic cellular activity of each tested culture type. Collagen content was determined by Erlich's hydroxyproline assay, as described by Reddy et al. [50] Hydroxyproline content was converted to collagen content using the equation: [ $\mu \mathrm{g}$ hydroxyproline $\times$ dilution factor $/ 0.13=\mu \mathrm{g}$ collagen] (Ignat'eva et al. [51]), because hydroxyproline is approximately $13 \%$ of the amino acids in human meniscal collagen 
[52]. Collagen Index was calculated using the following equation: [ $\mu$ g collagen/ ug dsDNA] to determine cellular collagen production. GAG and collagen content were also standardized to tissue dry weight and expressed as\% dry weight [53].

\section{Statistical methods}

Data was analyzed using a paired 2-tailed Student's t-test using statistical software (Graphpad Prism, La Jolla, CA). All data is reported as mean \pm Standard Error of the Mean (SEM). Statistical significance was declared at $P \leq 0.05$.

\section{Results}

The mean age of dogs was 5.4 years, (range 2-8 years). Breeds represented included: Labrador Retriever (3), Boston Bull Terrier, Australian Shepherd, Rottweiler (2), Doberman Pincer, Labrador cross, and mixed breed; 5 dogs were male neutered, 4 dogs were female spayed, and 1 was an intact female. As observed by a Diplomate of the American College of Veterinary Surgeons -Small Animal, all dogs had synovitis and osteophytosis, and grade 1-2 Outerbridge cartilage lesions [54].

\section{Cell culture, cell viability, and cellularity}

Cell culture: The mean wet weight of harvested synovium was $1.59 \mathrm{~g}$, (range: $0.15 \mathrm{~g}-4.8 \mathrm{~g}$ ). As found previously [28], the preponderance of cells harvested arthroscopically were red blood cells. A mean of $2.27 \times 10^{6} \pm 6.6 \times 10^{5}$ synoviocytes per dog were obtained at harvest. Time from plating at $4^{\text {th }}$ passage to hyperconfluency and commencement of spontaneous contraction off the plate floor was a median of 5 days (range 2.3 -8 days).

Timing of TSB synthesis was critical and needed to be performed upon first observation of cell sheet contraction as described above. Failure to immediately harvest HCS resulted in the formation of contracted masses. By the end of the 1st week of culture, TSB were able to be moved without unraveling. Long term culture with tension resulted in a sheet- like appearance of TSB, with some TSB appearing more translucent (Figure 3A) while others appeared more opaque (Figure 3B). Of the 9 attempted TSB made per dog, an average of 2.3 TSB per dog partially contracted off their wire hoops, forming an incomplete sheet or contracted mass, (Figure 3C) and were not analyzed in this study. One dog, a 7 year old male neutered Doberman pincer, produced hyperconfluent cell sheets that were thin and fragile and disintegrated upon manipulation, precluding formation of TSB in this individual. For the first 2 weeks after TSB were synthesized, the culture well media had become light orange by the time the daily media change was due, indicating a drop in $\mathrm{pH}$.

Viability: For monolayer culture cell viability was $99 \%$ for passages $1-3$. Mean cell viability of $4^{\text {th }}$ passage monolayer cells was $98.8 \% \pm 0.4$ versus passages $1-3$ $(\mathrm{P}=0.78)$. Mean cell viability of $\mathrm{HCS}$ was $93.3 \% \pm 1.7$ compared to $4^{\text {th }}$ passage cells $(P=0.04)$. TSB viability cell counts represented an estimation due to their 3 -dimensional structure. Cell viability of TSB was $74.9 \% \pm 5.6$, representing a decrease from $4^{\text {th }}$ passage cells and HCS $(\mathrm{P}=0.005$ and $\mathrm{P}=0.01$, respectively).

Double Stranded DNA Content: Percent tissue DNA content standardized to dry weight was $0.18 \% \pm 0.0002$ for HCS and $0.20 \% \pm 0.0003$ for TSB $(\mathrm{P}=0.5494)$.

Hematoxalin and Eosin Histologic Analysis: HCS contained fibroblastic type cells with light, homogenous, eosinophilic ECM. TSB had dense ECM organized in bands and sheets. TSB cells appeared round to fusiform with the long axis parallel to the vector of tension (Figure 4).

\section{Glycosaminoglycan content}

Dimethylmethylene Blue (DMMB) Assay: Percent GAG per dry weight was $1 \% \pm 0.0005$ for HCS and $1.8 \% \pm 0.001$ for TSB $(\mathrm{P}=0.001)$. On a cellular level, TSB synoviocytes produced more GAG per cell (per the Chondrogenic Index), at $10.7 \pm 1.4$ versus $6.2 \pm 0.7$ for $\operatorname{HCS}(\mathrm{P}=0.0052)$.

Toluidine Blue Histologic Analysis: All HCS had light homogenous GAG deposition in between cell layers. TSB contained regional GAG deposition (Figure 3). In TSB
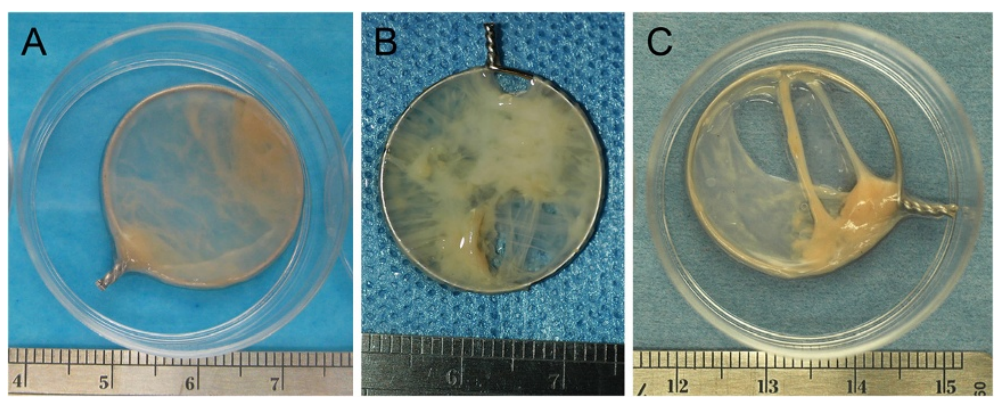

Figure 3 Tensioned synoviocyte bioscaffolds: Gross appearance of two representative tensioned synoviocyte bioscaffolds, ("TSB"; A and B); a TSB that contracted itself apart to form an incomplete TSB (C). 


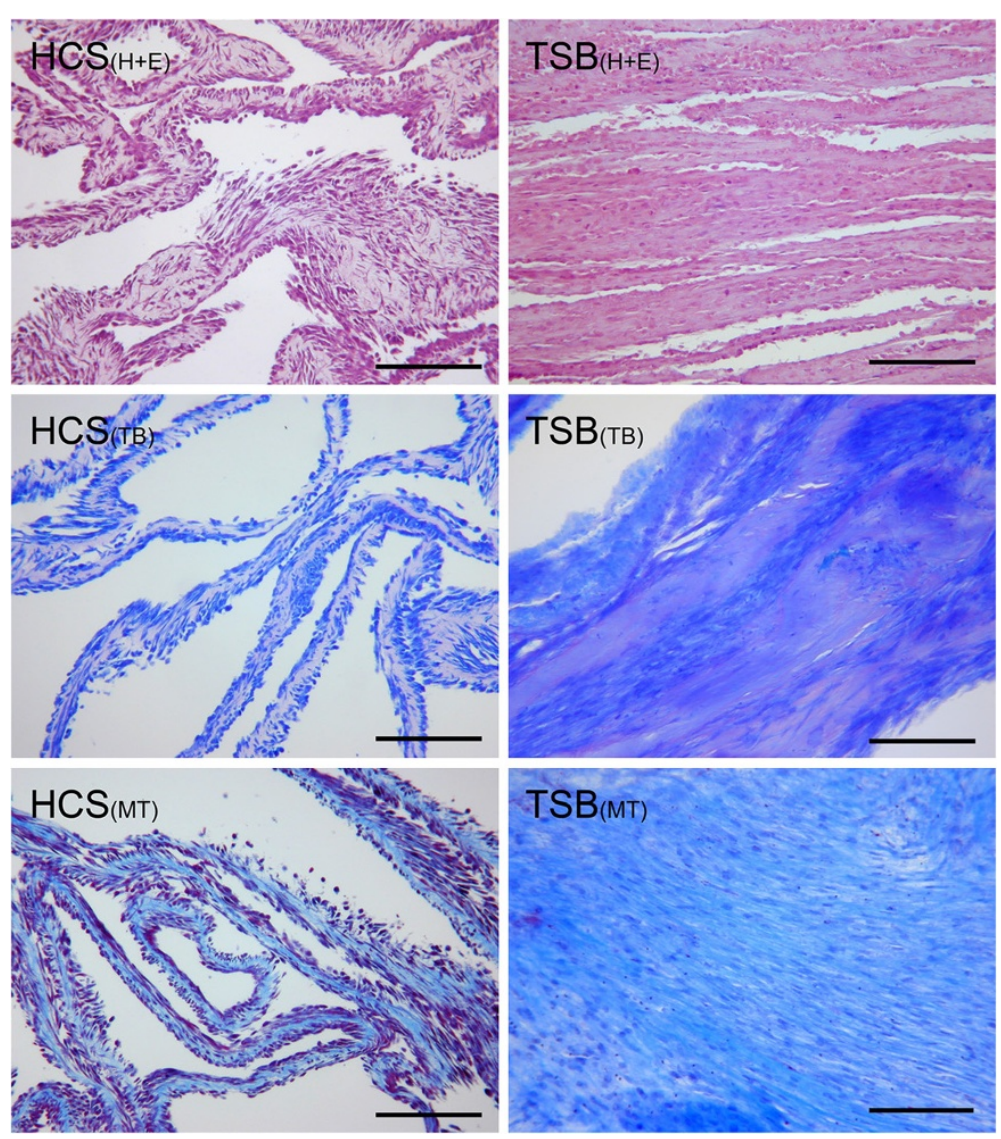

Figure 4 Histologic Analysis: Hematoxylin and Eosin stain ("H + E"), Toluidine Blue stain for GAG ("TB"), and Masson's Trichrome stain for collagen ("MT") of hyperconfluent cell sheets ("HCS") and tensioned synoviocyte bisocaffolds ("TSB"). 10X objective magnification, bar $=100 \mu \mathrm{m}$. Note the difference in tissue architecture between the thin HCS and dense bands and sheets of extracellular matrix in TSB.

from 2 dogs, some of the cells within GAG deposits were rounded in shape and were located in pseudo lacunae, similar to cells of the axial meniscus or articular cartilage.

\section{Collagen content}

Hydroxyproline Assay: TSB had higher collagen content at $13.1 \% \pm 0.02$ versus the $5.7 \% \pm 0.01$ of $\mathrm{HCS}(\mathrm{P}=0.0137)$. There was a trend that TSB synoviocytes produced more collagen per cell (per the Collagen Index), at $78.1 \pm 19.4$ versus $\mathrm{HCS}$ at $34.7 \pm 7.1(\mathrm{P}=0.05)$.

Trichrome Blue Histologic Analysis: Hyperconfluent monolayer synoviocyte sheets contained light collagen accumulation between cell layers. TSB contained dense collagen bands and sheets with cells oriented parallel to the vector of tension (Figure 4).

Collagen Immunohistochemistry: Mild patchy intracellular immunoreactivity to type I collagen was observed in all HCS. TSB 8 of 9 dogs had moderate to strong type I intracellular immunoreactivity over $50 \%$ of the cell population, with diffuse moderate immunoreactivity over the entire bioscaffold (Figure 5). One dog, a 7.3 year old female spayed mixed breed had mild intracellular and moderate extracellular immunoreactivity over $50 \%$ of the cell population and ECM area.

All HCS were negative for type II collagen immunoreactivity. In 7 dogs TSB had moderate to strong intracellular type II collagen immunoreactivity in $10-50 \%$ of cells while $1 \mathrm{dog}$ had mild immunoreactivity in $10 \%$ of cells (Figures 5). When examined at higher magnification these positively staining cells were grouped in clusters and had variable size and shape (Figure 6). TSB contained mild immunoreactivity to type II collagen over $10-50 \%$ of the bioscaffold ECM in 4 dogs and less than $10 \%$ in 3 dogs. One dog, an 8 year old male neutered Labrador, was negative for ECM type II collagen immunoreactivity, and the above listed 7.3 year old female spayed Labrador was also negative for intracellular and ECM type II collagen immunoreactivity.

\section{Alpha smooth muscle actin content}

Strong intracellular immunoreactivity to ASM was expressed in all HCS and TSB (Figure 5). 

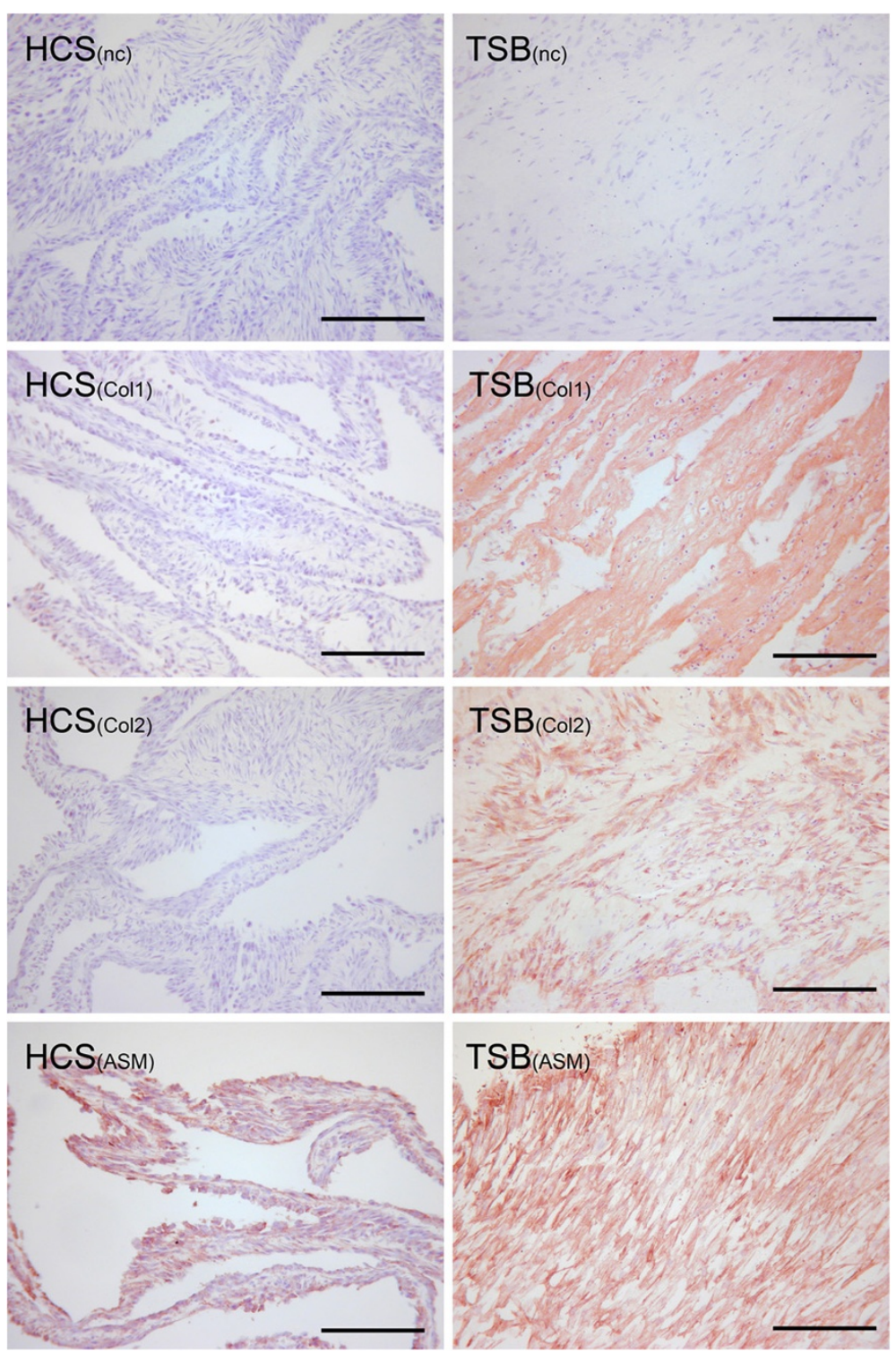

Figure 5 Immunohistochemistry analysis: Immunohistochemistry for collagens type I and II ("Col1 and Col2"), and alpha smooth muscle actin ("ASM"), of hyperconfluent cell sheets ("HCS") and tensioned synoviocyte bisocaffolds ("TSB"). Immunohistochemistry negative controls are delineated by "NC." 10X objective magnification, bar $=100 \mu \mathrm{m}$; Nova Red chromogen. In this example, TSB has moderate extracellular matrix staining for type I collagen, moderate intracellular immunoreactivity to type II collagen, and strong intracellular immunoreactivity to alpha smooth muscle actin.

\section{Discussion}

Of the many synthetic and biologic materials available to create scaffolds for meniscal tissue engineering, use of type I collagen has the closest functional significance. Type I collagen is the principal functional ECM component of the menisci, which is organized into circumferential bands to convert weight bearing forces into tensile hoop strains $[52,55,56]$. Because tension is a principle biomechanical stimulus for type I collagen formation in vivo $[38,57,58]$ and in vitro $[59,60]$, tension was utilized in the present study with the goal of producing a bioscaffold that is rich in type I collagen. Synoviocytes are mechanosensitive to tension [61,62]; synoviocytes cultured in monolayer at $50-60 \%$ confluence and exposed to static tension increase hyaluronic acid production by $57 \%$ [61]. In the present study long term culture with tension increased collagen content relative to HCS Long term culture with tension also produced tissue architecture consisting of bands and sheets of collagen, with longitudinally oriented cells, which is closer to the histologic appearance of the meniscus versus the architecture of HCS. This is the first report that static 


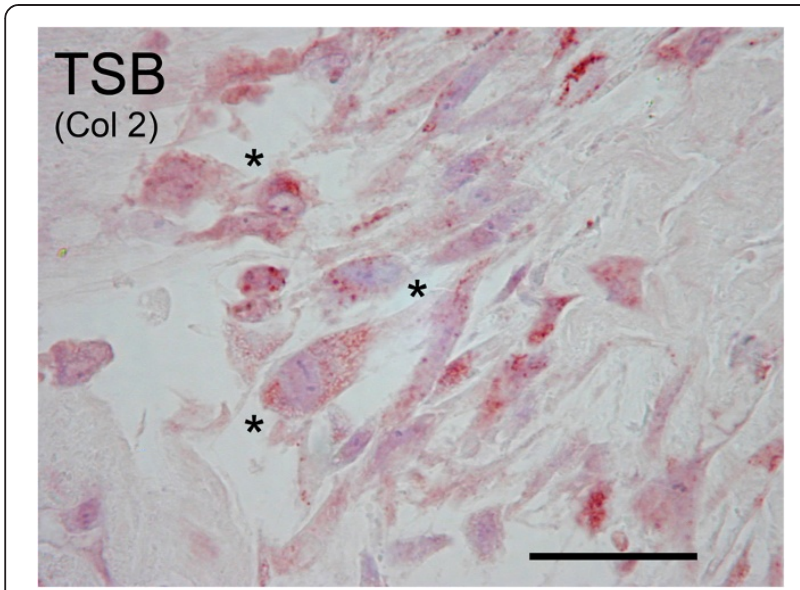

Figure 6 Evidence of mesenchymal progenitor cells: Immunohistochemistry for collagen type II in a tensioned synoviocyte bioscaffold ("TSB Col2"), showing variably shaped, large, fibroblastic cells (denoted by ${ }^{*}$ ) with moderate intracellular immunoreactivity to type II collagen; these cells are likely synovial mesenchymal progenitor cells. 20X objective magnification, bar $=50 \mu \mathrm{m}$; Nova Red chromagen.

tension over long term culture can increase collagen content towards a fibrocartilage tissue type in synovial fibroblasts.

The concentration of collagen in normal rabbit synovium per dry weight is approximately $11 \%$ [63], which is slightly lower than the $13 \%$ collagen of TSB, and higher than the $5 \%$ of HCS. The lower collagen content of HCS may reflect the diseased origin of our synovial tissues or may be a result of the artificial monolayer culture environment. At this time the ideal collagen content of meniscal implants is not known, but maximizing collagen content would likely improve the strength and durability of a surgical implant.

GAG and type II collagen are major ECM synthesis targets in meniscal tissue engineering because they are functionally critical components of the meniscus, particularly in the non- healing, axial, avascular zone $[38,45]$. In the present study TSB were $1.8 \%$ GAG, and as observed histologically, the majority of TSB contained type II collagen. In contrast, native synovium produces collagen types I,III, and VI [64], and contains only $0.7 \%$ of GAG per dry weight [63]. In this study, regional deposition of GAG and type II collagen were synthetic products of mesenchymal synoviocyte progenitor cells [22] (Figure 6), the numbers of which were increased by the high concentration of FBS and long term culture $[65,66]$. The variation seen in type II collagen formation between dogs may have been due to variable numbers of mesenchymal progenitor cells per dog, and their varying differentiation potential within each individual [67]. Another potential mechanism for GAG and type II collagen deposition involves biomechanical stimulation. Type II collagen and GAG form when synoviocytes are exposed to compressive loads in vitro [68], which may have been generated in the TSB during tensioning due to Poisson's effect. Poisson's effect states that when a material is tensioned, it contracts transversely to the vector of pull (which can be observed when stretching a rubber band, for example), thereby forming regions of compression within the material. In addition, FBS does contain chondrogenic growth factors, which support joint growth of the fetal calf in utero; however the quantity and proportion of these factors were not determined in this study.

In meniscal development, the undifferentiated meniscal primordia are highly cellular with minimal ECM [69], which mature into fibrocartilage with few cells and dense ECM. Because tissue differentiation is highly dependent on cell density [70], we attempted to recapitulate this developmental process with long term culture of highly cellular HCS tensioned as TSB. While ECM did increase in TSB (Figure 3), total dsDNA concentration, as a measure of tissue cellularity, was not different between HCS and TSB. Further, cell viability dropped over time, possibly due to apoptosis resulting from prolonged cell culture. Additionally, culture of highly cellular TSB in $9 \mathrm{~mL}$ of media with once daily media changes limited nutrient delivery and resulted in a daily $\mathrm{pH}$ drop, contributing to cell mortality.

Canine synovium expresses alpha smooth muscle actin [71]. In the present study, the presence of ASM in HCS and TSB explains the contractile behavior of HCS, maintenance of tension of TSB, as well as contraction of some TSB off their wire hoops. This contractile behavior of a bioscaffold implant could be utilized to assist in apposition of meniscal wound edges for augmentation of meniscal healing.

In prior research, we found that culture of canine synoviocytes as HCS in monolayer over a 30 day period resulted in spontaneously contracted masses with poor cell viability, poor ECM formation, and poor handling characteristics [28]. However, in the present study, we did not repeat long term monolayer culture as a control to TSB, which is a weakness in our study.

\section{Conclusions}

In conclusion, we partially accept our hypothesis, as addition of tension over longer term culture in TSB resulted in higher GAG and collagen content, versus HCS. DNA content was not different between TSB and HCS. However, cell viability dropped over time in TSB. Thus, TSB is a viable model for future in vitro meniscal tissue engineering studies, but further investigation is required to reduce TSB cell mortality, increase collagen content, and reduce inter-patient variability of these constructs. 


\section{Abbreviations}

ASM: Alpha smooth muscle actin; Calcein -AM: Acetomethoxy- calcein; DMEM: Dulbecco's modified Eagle's media; hgDMEM: High glucose Dulbecco's modified Eagle's media; sDMEM: Supplemented Dulbecco's modified Eagle's media; ECM: Extracellular matrix; FBS: Fetal bovine serum; GAG: Glycosaminoglycans; HCS: Hyperconfluent monolayer cell sheet; IHC: Immunohistochemistry; SEM: Standard error of the mean; TBS: Tris buffered saline; TSB: Tensioned synoviocyte bioscaffold.

\section{Competing interests}

The authors declare that they have no competing interests.

\section{Authors' contributions}

JW conceived of and designed the study, participated in cell culture and data acquisition, and drafted the manuscript. LB and GB were DVM students of the College of Veterinary Medicine at the time of this study, and carried out cell culture, tissue analysis assays, and helped with study design. JO organized and performed assays and coordindated study participants. All authors read and approved the final manuscript.

\section{Acknowledgements}

The authors would like give Dr. Wendy Baltzer, DVM, PhD, DACVS, very special thanks for contribution of some of the synovial tissue cultured in this study.

Author disclosure statement: The authors do not have any conflicts of interest to disclose. This study was funded by Oregon State University, College of Veterinary Medicine.

Presented in part as a podium presentations at the Veterinary Orthopedic Society Conference, Aspen CO, March 2011.

\section{Author details}

${ }^{1}$ Clinical Sciences, College of Veterinary Medicine, Oregon State University, Corvallis, OR, USA. ${ }^{2}$ Current address: WestVet Specialty Center, Garden City, ID, USA. ${ }^{3}$ Current address: Peace River Veterinary Clinic, Punta Gorda, FL, USA.

Received: 3 April 2013 Accepted: 25 November 2013

Published: 3 December 2013

\section{References}

1. Luther JK, Cook CR, Cook JL: Meniscal release in cruciate ligament intact stifles causes lameness and medial compartment cartilage pathology in dogs 12 weeks postoperatively. Vet Surg 2009, 38:520-529.

2. Cox JS, Nye CE, Schaefer WW, Woodstein IJ: The degenerative effects of partial and total resection of the medial meniscus in dogs' knees. Clin Orthop Relat Res 1975, 109:178-183.

3. Johnson KA, Francis DJ, Manley PA, Chu Q, Caterson B: Comparison of the effects of caudal pole hemi-meniscectomy and complete medial meniscectomy in the canine stifle joint. Am J Vet Res 2004, 65:1053-1060.

4. Lindhorst E, Vail TP, Guilak F, Wang H, Setton LA, Vilim V, Kraus VB: Longitudinal characterization of synovial fluid biomarkers in the canine meniscectomy model of osteoarthritis. J Orthop Res 2000, 18:269-280.

5. Wyland DJ, Guilak F, Elliott DM, Setton LA, Vail TP: Chondropathy after meniscal tear or partial meniscectomy in a canine model. $J$ Orthop Res 2002, 20:996-1002.

6. Cicuttini FM, Forbes A, Yuanyuan W, Rush G, Stuckey SL: Rate of knee cartilage loss after partial meniscectomy. J Rheumatol 2002, 29:1954-1956.

7. Bradley MP, Fadale PD, Hulstyn MJ, Muirhead WR, Lifrak JT: Porcine small intestine submucosa for repair of goat meniscal defects. Orthopedics 2007, 30:650-656

8. Cook JL, Fox DB, Malaviya P, Tomlinson JL, Kuroki K, Cook CR, Kladakis S: Long-term outcome for large meniscal defects treated with small intestinal submucosa in a dog model. Am J Sports Med 2006, 34:32-42.

9. Cook JL, Tomlinson JL, Kreeger JM, Cook CR: Induction of meniscal regeneration in dogs using a novel biomaterial. Am J Sports Med 1999, 27:658-665.

10. de Groot JH, de Vrijer R, Pennings AJ, Klompmaker J, Veth RP, Jansen HW: Use of porous polyurethanes for meniscal reconstruction and meniscal prostheses. Biomater 1996, 17:163-173.

11. Kobayashi $M$, Chang YS, Oka M: A two year in vivo study of polyvinyl alcohol-hydrogel (PVA-H) artificial meniscus. Biomater 2005, 26:3243-3248.
12. Weinand C, Peretti GM, Adams SB Jr, Bonassar LJ, Randolph MA, Gill TJ: An allogenic cell-based implant for meniscal lesions. Am J Sports Med 2006, 34:1779-1789.

13. Kang SW, Son SM, Lee JS, Lee ES, Lee KY, Park SG, Park JH, Kim BS: Regeneration of whole meniscus using meniscal cells and polymer scaffolds in a rabbit total meniscectomy model. J Biomed Mater Res A 2006, 78:659-671.

14. Tienen TG, Heijkants RG, Buma P, De Groot JH, Pennings AJ, Veth RP: A porous polymer scaffold for meniscal lesion repair-a study in dogs. Biomater 2003, 24:2541-2548.

15. Esposito AR, Moda M, Cattani SM, de Santana GM, Barbieri JA, Munhoz MM, Cardoso TP, Barbo ML, Russo T, D'Amora U, et al: PLDLA/PCL-T Scaffold for Meniscus Tissue Engineering. Biores Open Access 2013, 2:138-147.

16. Puetzer $\mathrm{L}$, Bonassar $\mathrm{LJ}$ : High density type I collagen gels for tissue engineering of whole menisci. Acta Biomater 2013, 9:7787-7795.

17. Stone KR, Rodkey WG, Webber R, McKinney L, Steadman JR: Meniscal regeneration with copolymeric collagen scaffolds. In vitro and in vivo studies evaluated clinically, histologically, and biochemically. Am J Sport Med 1992, 20:104-111.

18. Hansen R, Bryk E, Vigorita V: Collagen scaffold meniscus implant integration in a canine model: A histological analysis. J Orthop Res 2013. in press.

19. Pulliainen $O$, Vasara Al, Hyttinen MM, Tiitu V, Valonen P, Kellomaki M, Jurvelin JS, Peterson L, Lindahl A, Kiviranta I, et al: Poly-L-D-lactic acid scaffold in the repair of porcine knee cartilage lesions. Tissue Eng 2007, 13:1347-1355.

20. Gleghorn JP, Doty SB, Warren RF, Wright TM, Maher SA, Bonassar LJ: Analysis of frictional behavior and changes in morphology resulting from cartilage articulation with porous polyurethane foams. J Orthop Res 2010, 28:1292-1299.

21. Stapleton TW, Ingram J, Fisher J, Ingham E: Investigation of the regenerative capacity of an acellular porcine medial meniscus for tissue engineering applications. Tissue Eng Part A 2010, 17:231-242.

22. Zhang N, Dietrich MA, Lopez MJ: Canine Intra-Articular Multipotent Stromal Cells (MSC) From Adipose Tissue Have the Highest In Vitro Expansion Rates, Multipotentiality, and MSC Immunophenotypes. Vet Surg 2013, 42:137-146.

23. Sakaguchi Y, Sekiya I, Yagishita K, Muneta T: Comparison of human stem cells derived from various mesenchymal tissues: superiority of synovium as a cell source. Arthritis Rheum 2005, 52:2521-2529.

24. Futami I, Ishijima M, Kaneko H, Tsuji K, Ichikawa-Tomikawa N, Sadatsuki R, Muneta T, Arikawa-Hirasawa E, Sekiya I, Kaneko K: Isolation and characterization of multipotential mesenchymal cells from the mouse synovium. PLoS One 2012, 7:e45517.

25. Yoshimura H, Muneta T, Nimura A, Yokoyama A, Koga H, Sekiya I: Comparison of rat mesenchymal stem cells derived from bone marrow, synovium, periosteum, adipose tissue, and muscle. Cell Tissue Res 2007 327:449-462.

26. Warnock JJ, Fox DB, Stoker AM, Cook JL: Evaluation of in vitro growth factor treatments on fibrochondrogenesis by synovial membrane cells from osteoarthritic and nonosteoarthritic joints of dogs. Am J Vet Res 2011, 72:500-511.

27. Warnock JJ, Duesterdieck-Zellmer KF, Bobe G, Baltzer WI, Ott J: Synoviocyte neotissues towards in vitro meniscal tissue engineering. Res Vet Sci 2013. in press.

28. Warnock JJ, Baltzer WI, Duesterdieck-Zellmer K, Ott J: Minimally invasive synovium harvest for potential use in meniscal tissue engineering. Res Vet Sci 2012, 93:1472-80.

29. Arnoczky SP, DiCarlo EF, O'Brien SJ, Warren RF: Cellular repopulation of deep-frozen meniscal autografts: an experimental study in the dog. Arthroscopy 1992, 8:428-436.

30. Smith TJ, Baltzer WI, Lohr C, Stieger-Vanegas SM: Primary synovial osteochondromatosis of the stifle in an English Mastiff. Vet Comp Orthop Traumatol 2012, 25:160-166.

31. Tienen TG, Heijkants RG, de Groot JH, Schouten AJ, Pennings AJ, Veth RP, Buma P: Meniscal replacement in dogs. Tissue regeneration in two different materials with similar properties. J Biomed Mater Res B Appl Biomater 2006, 76:389-396.

32. Kobuna Y, Shirakura K, Niijima M: Meniscal repair using a flap of synovium. An experimental study in the dog. Am J Knee Surg 1995, 8:52-55.

33. Shirakura K, Niijima M, Kobuna Y, Kizuki S: Free synovium promotes meniscal healing. Synovium, muscle and synthetic mesh compared in dogs. Acta Orthop Scand 1997, 68:51-54. 
34. Ochi M, Mochizuki Y, Deie M, Ikuta Y: Augmented meniscal healing with free synovial autografts: an organ culture model. Arch Orthop Trauma Surg 1996, 115:123-126.

35. Cisa J, Basora J, Madarnas P, Ghibely A, Navarro-Quilis A: Meniscal repair by synovial flap transfer. Healing of the avascular zone in rabbits. Acta Orthop Scand 1995, 66:38-40.

36. Moriguchi $Y$, Tateishi K, Ando W, Shimomura K, Yonetani Y, Tanaka Y, Kita K, Hart DA, Gobbi A, Shino K, et al: Repair of meniscal lesions using a scaffold-free tissue-engineered construct derived from allogenic synovial MSCs in a miniature swine model. Biomater 2013, 34:2185-2193.

37. Vasanjee SC, Paulsen D, Hosgood G, Robinson SO, Lopez MJ: Characterization of normal canine anterior cruciate ligament-associated synoviocytes. J Orthop Res 2008, 26:809-815.

38. Kambic HE, McDevitt CA: Spatial organization of types I and II collagen in the canine meniscus. J Orthop Res 2005, 23:142-149.

39. Ahluwalia S, Fehm M, Murray MM, Martin SD, Spector M: Distribution of smooth muscle actin-containing cells in the human meniscus. J Orthop Res 2001, 19:659-664.

40. Kambic HE, Futani H, McDevitt CA: Cell, matrix changes and alpha-smooth muscle actin expression in repair of the canine meniscus. Wound Repair Regen 2000, 8:554-561.

41. Spector M: Musculoskeletal connective tissue cells with muscle: expression of muscle actin in and contraction of fibroblasts, chondrocytes, and osteoblasts. Wound Repair Regen 2001, 9:11-18.

42. Adams ME, Ho YA: Localization of glycosaminoglycans in human and canine menisci and their attachments. Connect Tissue Res 1987, 16:269-279.

43. Stephan JS, McLaughlin RM Jr, Griffith G: Water content and glycosaminoglycan disaccharide concentration of the canine meniscus. Am J Vet Res 1998, 59:213-216.

44. Nakano T, Dodd CM, Scott PG: Glycosaminoglycans and proteoglycans from different zones of the porcine knee meniscus. J Orthop Res 1997, 15:213-220.

45. Valiyaveettil M, Mort JS, McDevitt CA: The concentration, gene expression, and spatial distribution of aggrecan in canine articular cartilage, meniscus, and anterior and posterior cruciate ligaments: a new molecular distinction between hyaline cartilage and fibrocartilage in the knee joint. Connect Tissue Res 2005, 46:83-91.

46. Strober W: Trypan blue exclusion test of cell viability. Curr Protoc Immunol 2001, Appendix 3:Appendix 3B.

47. Wakshlag JJ, Peters-Kennedy J, Bushey JJ, Loftus JP: 5-lipoxygenase expression and tepoxalin-induced cell death in squamous cell carcinomas in cats. Am J Vet Res 2011, 72:1369-1377.

48. Farndale RW, Buttle DJ, Barrett AJ: Improved quantitation and discrimination of sulphated glycosaminoglycans by use of dimethylmethylene blue. Biochim Biophys Acta 1986, 883:173-177.

49. Li J, Pei M: Optimization of an in vitro three-dimensional microenvironment to reprogram synovium-derived stem cells for cartilage tissue engineering. Tissue Eng Part A 2011, 17:703-712

50. Reddy GK, Enwemeka CS: A simplified method for the analysis of hydroxyproline in biological tissues. Clin Biochem 1996, 29:225-229.

51. Ignat'eva NY, Danilov NA, Averkiev SV, Obrezkova MV, Lunin W, Sobol EN: Determination of Hydroxyproline in Tissues and the Evaluation of the Collagen Content of the Tissues. J Analytical Chem 2007, 62:51-57.

52. Fithian DC, Kelly MA, Mow VC: Material properties and structure-function relationships in the menisci. Clin Orthop Relat Res 1990, 252:19-31.

53. Eyre DR, Wu JJ: Collagen of fibrocartilage: a distinctive molecular phenotype in bovine meniscus. FEBS letters 1983, 158:265-270.

54. Outerbridge R: The etiology of chondromalacia patellae. J Bone Joint Surg 1961, 43:752-757.

55. Jones RS, Keene GC, Learmonth DJ, Bickerstaff D, Nawana NS, Costi JJ, Pearcy MJ: Direct measurement of hoop strains in the intact and torn human medial meniscus. Clin Biomech (Bristol, Avon) 1996, 11:295-300.

56. Ahmed AM: A pressure distribution transducer for in-vitro static measurements in synovial joints. J Biomech Eng 1983, 105:309-314

57. Cheung HS: Distribution of type I, II, III and V in the pepsin solubilized collagens in bovine menisci. Connect Tissue Res 1987, 16:343-356.

58. Spindler KP, Miller RR, Andrish JT, McDevitt CA: Comparison of collagen synthesis in the peripheral and central region of the canine meniscus. Clin Orthop Relat Res 1994, 303:256-263.

59. Baker BM, Shah RP, Huang AH, Mauck RL: Dynamic tensile loading improves the functional properties of mesenchymal stem cell-laden nanofiber-based fibrocartilage. Tissue Eng 2011, 17:1445-1455.
60. Deng D, Liu W, Xu F, Yang Y, Zhou G, Zhang WJ, Cui L, Cao Y: Engineering human neo-tendon tissue in vitro with human dermal fibroblasts under static mechanical strain. Biomater 2009, 30:6724-6730.

61. Momberger TS, Levick JR, Mason RM: Hyaluronan secretion by synoviocytes is mechanosensitive. Matrix Biol 2005, 24:510-519.

62. Sakamoto $Y$, Ishijima M, Kaneko H, Kurebayashi N, Ichikawa N, Futami I, Kurosawa H, Arikawa-Hirasawa E: Distinct mechanosensitive Ca2+ influx mechanisms in human primary synovial fibroblasts. J Orthop Res 2010, 28:859-864.

63. Price FM, Levick JR, Mason RM: Glycosaminoglycan concentration in synovium and other tissues of rabbit knee in relation to synovial hydraulic resistance. J Physio/ 1996, 495:803-820.

64. Okada Y, Naka K, Minamoto T, Ueda Y, Oda Y, Nakanishi I: Timpl R: localization of type VI collagen in the lining cell layer of normal and rheumatoid synovium. Lab Invest 1990, 63:647-656.

65. Teramura T, Fukuda K, Kurashimo S, Hosoi Y, Miki Y, Asada S, Hamanishi C: Isolation and characterization of side population stem cells in articular synovial tissue. BMC Musculoskeletal Dis 2008, 9:86.

66. He F, Chen X, Pei M: Reconstruction of an in vitro tissue-specific microenvironment to rejuvenate synovium-derived stem cells for cartilage tissue engineering. Tissue Eng Part A 2009, 15:3809-3821.

67. Karystinou A, Dell'Accio F, Kurth TB, Wackerhage H, Khan IM, Archer CW Jones EA, Mitsiadis TA, De Bari C: Distinct mesenchymal progenitor cell subsets in the adult human synovium. Rheumatology (Oxford) 2009, 48:1057-1064

68. Sakao K, Takahashi KA, Arai Y, Inoue A, Tonomura H, Saito M, Yamamoto T, Kanamura N, Imanishi J, Mazda O, et al: Induction of chondrogenic phenotype in synovium-derived progenitor cells by intermittent hydrostatic pressure. Osteoarthritis Cartilage 2008, 16(7):805-814.

69. Clark CR, Ogden JA: Development of the menisci of the human knee joint. Morphological changes and their potential role in childhood meniscal injury. J Bone Joint Surg Am 1983, 65:538-547.

70. Gurdon JB: A community effect in animal development. Nature 1988 336:772-774.

71. Vickers SM, Johnson LL, Zou LQ, Yannas IV, Gibson LJ, Spector M: Expression of alpha-smooth muscle actin by and contraction of cells derived from synovium. Tissue Eng 2004, 10:1214-1223.

doi:10.1186/1746-6148-9-242

Cite this article as: Warnock et al.: In vitro synthesis of tensioned synoviocyte bioscaffolds for meniscal fibrocartilage tissue engineering. BMC Veterinary Research 2013 9:242

\section{Submit your next manuscript to BioMed Central and take full advantage of:}

- Convenient online submission

- Thorough peer review

- No space constraints or color figure charges

- Immediate publication on acceptance

- Inclusion in PubMed, CAS, Scopus and Google Scholar

- Research which is freely available for redistribution
C) Biomed Central 